\title{
Sexual Dimorphism in the Olfactory System of a Solitary and a Eusocial Bee Species
}

\author{
Martin Streinzer, ${ }^{1,2}$ Christina Kelber, ${ }^{2,3}$ Sarah Pfabigan, ${ }^{1}$ Christoph J. Kleineidam, ${ }^{2,4}$ \\ and Johannes Spaethe ${ }^{1,2 *}$ \\ ${ }^{1}$ Department of Evolutionary Biology, Faculty of Life Sciences, University of Vienna, A 1090 Vienna, Austria \\ ${ }^{2}$ Department of Behavioral Physiology and Sociobiology, Biozentrum, University of Würzburg, D 97074 Würzburg, Germany \\ ${ }^{3}$ Department of Biology, Technical University of Darmstadt, D 64287 Darmstadt, Germany \\ ${ }^{4}$ Department of Biology, University of Konstanz, D 78457 Konstanz, Germany
}

\section{ABSTRACT}

Sexually dimorphic sensory systems are common in Hymenoptera and are considered to result from sex-specific selection pressures. An extreme example of sensory dimorphism is found in the solitary bee tribe Eucerini. Males of long-horned bees bear antennae that exceed body length. This study investigated the pronounced sexual dimorphism of the peripheral olfactory system and its representation in higher brain centers of the species Eucera berlandi. Eucera males have elongated antennae, with 10 times more pore plates and three times more olfactory receptor neurons than females. The male antennal lobe (AL) comprises fewer glomeruli than the female $\mathrm{AL}(\sim 100$ vs. $\sim 130)$, of which four are male-specific macroglomeruli. No sex
\end{abstract}

differences were found in the relative volume of the mushroom bodies, a higher order neuropil essential for learning and memory in Hymenoptera. Compared with the Western honeybee, the degree of sexual dimorphism in Eucera is more pronounced at the periphery. In contrast, sex differences in glomerular numbers are higher in the eusocial honeybee and a sexual dimorphism of the relative investment in mushroom body tissue is observed only in Apis. The observed differences between the eusocial and the solitary bee species may reflect differences in male-specific behavioral traits and associated selection pressures, which are discussed in brief. J. Comp. Neurol. 521:2742-2755, 2013.

INDEXING TERMS: Eucera berlandi; Apis mellifera; mate detection; olfaction; antennal lobe

Insects sense odors with olfactory sensilla located on the antenna. Individual sensilla house a few to several dozen olfactory receptor neurons (ORNs), which usually express only a single olfactory receptor gene, coupled with the coreceptor Orco; together they account for odor specificity (de Bruyne and Baker, 2008; Vosshall and Hansson, 2011). ORNs project into the antennal lobes (ALs), where they synapse with local interneurons and projection neurons, thereby forming functional units called glomeruli (Boeckh and Tolbert, 1993). The number of glomeruli is assumed to reflect the number of olfactory receptor types expressed in the antenna (de Bruyne and Baker, 2008). Olfactory information is subsequently conveyed to higher processing centers, such as the lateral protocerebrum and the mushroom bodies (MBs), where sensory integration and memory formation occur (Farris, 2005; Strausfeld et al., 1998).

Specializations along the olfactory pathway are common and generally reflect specific odor-guided behaviors that are performed throughout life (Hansson and Stensmyr, 2011). Selection pressure on various traits of the olfactory system (and other sensory systems) vary between taxa, sexes, and life styles (e.g., social vs. solitary life) and cause variation in the organization and complexity of the olfactory system (Hansson and Stensmyr, 2011; Kleineidam and Rössler, 2009; Strausfeld and Reisenman, 2009) and higher brain centers (El Jundi et al., 2009; Gronenberg, 2008). The largest body of knowledge on sex-specific odor and pheromone detection and processing originates from Lepidoptera (Hansson and

Grant sponsor: Forschungsstipendium; Grant number: F 444 (to M.S.); Grant sponsor: Austrian Academy of Sciences at the Department of Evolutionary Biology, University of Vienna (to M.S.).

*CORRESPONDENCE TO: Johannes Spaethe, Department of Behavioral Physiology and Sociobiology, Biozentrum, University of Würzburg, Am Hubland, D 97074 Würzburg, Germany.

E mail: johannes.spaethe@uni wuerzburg.de 
Stensmyr, 2011). Adaptations of the olfactory system have further been described from a wide range of insect taxa, such as Diptera, Coleoptera, Hymenoptera, and Blattodea (Hansson and Stensmyr, 2011; Kelber et al., 2010; Schachtner et al., 2005).

Differences between sexes usually result from species-specific selection pressures and task differences during life. In bees, females usually seek to find or build nests, forage for food, and provision the brood, whereas males focus predominantly on the search for females with which to mate (Alcock et al., 1978). As a consequence, adaptations of the olfactory system differ between the sexes, which are often apparent in a distinct external sexual dimorphism.

An outstanding example of such a dimorphism is observed in the solitary bee tribe Eucerini (Hymenoptera, Apidae). Male long-horned bees bear antennae that exceed body length, whereas those of the female are relatively short (Michener, 2007). The physiological and functional consequences of the long antennae, as well as the consequences of the pronounced morphological dimorphism on the olfactory pathway, are hitherto unexplored. Solitary bees are vastly underrepresented in comparative studies on the olfactory system of insects and only one of the $\sim 20,000$ species worldwide, the Western honeybee, has been comprehensively investigated. Apis mellifera also shows an extreme sexual dimorphism of the olfactory system. Drones possess enlarged antennae that house a higher number of olfactory sensilla than workers (Esslen and Kaissling, 1976; Nishino et al., 2009). The additional bias in multiplication of sex-pheromone-sensitive ORNs in honeybee drones causes an enlargement of the corresponding glomeruli in the AL (Arnold et al., 1985; Brockmann et al., 1998; Wanner et al., 2007). As a consequence, the antenna is selectively tuned to the detection of the long-distance sex pheromone component (2E)-9-oxodecenoic acid (9-ODA; Brockmann et al., 1998; Sandoz, 2006; Wanner et al., 2007). Furthermore, honeybee sexes differ greatly in the number of glomeruli in the antennal lobe, a feature that seems to be unique in Hymenoptera (Schachtner et al., 2005). In Apis, the overall number of $A L$ glomeruli in drones is about $40 \%$ lower than that in workers (Arnold et al., 1985).

This article describes the conspicuous olfactory dimorphism of the solitary long-horned bee species Eucera berlandi and compares it with the olfactory system of the eusocial Apis mellifera. Males of both species presumably face strong sexual selection pressures, and their scramble competition mating system is known to promote the evolution of enhanced sensory and locomotion capabilities (Andersson and Iwasa, 1996). The elaboration of sexually selected traits, however, is assumed to counter and interact with natural selection and is thus limited. In hon- eybees, drones are provided with food and shelter by their colony, whereas Eucera males live fully autonomous lives. We speculate that additional selection pressures in Eucera may limit the allocation of sensory resources for mate detection. Therefore, we expect that the investment in olfactory systems and higher order processing is less dimorphic in the solitary bee species than in Apis. To test our prediction, we measured and compared the numbers of olfactory sensilla and ORNs, the presence/absence of macroglomeruli, the numbers of glomeruli in the $A L$, and the volumes of the mushroom bodies.

\section{MATERIALS AND METHODS}

\section{Study species Eucera (Synhalonia) berlandi (Dusmet, 1926)}

The long-horned bee $E$. berlandi (for simplification referred to as Eucera throughout this article) is a solitary eucerine bee common to the Mediterranean region. Long-horned bees show an extreme sexual dimorphism, and the males' antennae rank among the longest in bees (Michener, 2007). Males emerge from underground nests prior to females and patrol the nesting sites, awaiting the appearance of the females. Once females have emerged, males rely on olfactory and visual signals to detect females with which to mate (Danesch and Danesch, 1976; Shimron and Hefetz, 1985; Streinzer et al., 2009). Most female solitary bees are assumed to mate only once, so the first successful male receives full reproduction success from that female (Paxton, 2005; Shimron and Hefetz, 1985). The males of E. berlandi serve as specific pollinator of a Mediterranean sexually deceptive orchid and have been extensively used for behavioral studies in this context (e.g., Streinzer et al., 2009). Furthermore, the chemical mimicry of the sex pheromones by the plant allows for future characterization of the behaviorally active semiochemicals. All male and female specimens used in this study were collected on Crete (Greece) and Istria (Croatia).

\section{Apis mellifera Linné, 1758}

The Western honeybee (for simplification referred to as Apis throughout this article) is a highly eusocial bee. Colonies persist for several years. To reproduce, drones and virgin queens are produced only during a short period in the summer season. Males temporarily leave the colony, congregate at prominent landmarks, and wait for queens to enter these congregations during their mating flight (Winston, 1991). When a queen enters such a congregation, the drones detect her by both olfactory and visual means. Queens usually mate multiple times, whereas drones mate only once and die shortly after (Winston, 1991). All honeybee specimens used in this study were 
obtained from the bee facility at the University of Würzburg.

In the honeybee colony, the majority of tasks (e.g., nest site selection and nest construction, foraging, orientation and flower detection while foraging, thermoregulation, and brood care) are performed by workers (Winston, 1991). Although the queen is the reproductive female, the sterile workers represent the functional equivalent to the female in solitary bees, and we thus compare our data on the solitary bee species with that on the honeybee workers.

Previous studies in eusocial and solitary bees indicate that the volume of the brain and brain structures, in particular the mushroom bodies, increases with age and experience (Withers et al., 1993, 2008). We did not control for individual age and experience in the specimens used. However, all individuals were collected at an age when they were already foraging for food and nectar (females) or performing mating activities (males). We are thus confident that the major volume change, which is associated with the transition from indoor tasks to outdoor foraging and mating behavior (Fahrbach et al., 1997; Withers et al., 1993, 2008), has already taken place.

\section{Antennal morphology}

Ethanol-stored antennae of Eucera males and females were mounted on a microscope slide and photographed at $\times 15$ magnification using a stereo microscope (Nikon SMZ-U, Tokyo, Japan) equipped with a digital camera (Nikon DS-Fi1). Antennal length and width were measured from photographs in ImageJ (National Institute of Mental Health, Bethesda, MD). To compare the total number of olfactory sensilla between sexes, we counted sensilla placodea (pore plates; PPs) on the antenna. PPs constitute the most abundant olfactory sensilla, and their role in sensing odors and sex pheromone components has been demonstrated in the honeybee (Kaissling and Renner, 1968; Vareschi, 1971). One antenna was cut from male and female individuals of Eucera and covered with nail polish. After drying, the nail polish coat was removed from the antenna, and the negative imprint was used for further investigations. The imprint was cut with a microblade along the length axis, flattened, and mounted onto a microscope slide and subsequently photographed with a microscope (Nikon LaboPhot II equipped with a DS-Fi 1 camera) at $\times 40$ and $\times 100$ magnifications. The overlapping sections were stitched together in Adobe Photoshop CS2 (Adobe Systems, San Jose, CA). PPs could be easily recognized on the imprint surface (see Fig. 1) and were counted manually in Image J. Additionally, we measured PP size (length and width) of 30 randomly selected PPs in one individual of each sex. Some, but not all, of the other sensilla types could also be unambiguously classified with the technique used (see Fig. 1; see also Riveros and Gronenberg, 2010). The antennal surface was measured from the antennal imprint by tracing the outlines. Surface measurements and PP counts were performed on the flagellum segments $2-10$ in females and 2-11 in males, because only these segments are equipped with PPs. Antennal measurements of Apis were taken from the literature (Esslen and Kaissling, 1976).

\section{Number of ORNs}

Antennae were cut from immobilized Eucera bees at the base of the most basal flagellum segment. To facilitate perfusion of the fixative (Karnovsky solution: $2.5 \%$ glutaraldehyde, $2 \%$ paraformaldehyde in $0.1 \mathrm{M}$ sodium cacodylate buffer), only a short piece of two or three basal segments was fixed for 1 hour at RT. Antennae were rinsed three times in $0.1 \mathrm{M}$ sodium cacodylate buffer and postfixed with $1 \%$ osmium tetroxide for 2 hours. After thoroughly rinsing in cacodylate buffer, segments were dehydrated in an ascending alcohol series (50\%, 70\%, 80\%, 96\%, $3 \times$ 100\%, 10 minutes each) and embedded in Agar Low Viscosity Resin (Agar Scientific, Essex, United Kingdom). Semithin (1-2 $\mu \mathrm{m})$ and ultrathin $(70 \mathrm{~nm})$ sections were cut with glass or diamond knives (type ultra, size 2.5, $45^{\circ}$ knife angle; Diatome, Biel, Switzerland) on an EM UC6 (Leica Microsystems, Wetzlar, Germany). The sections were stained for light microscopy using 1\% azure II and 1\% methylene blue in an aqueous 1\% borax solution (diluted 1:9 in aqua bidest) for 15 seconds at $60^{\circ} \mathrm{C}$. Sections were photographed on a light microscope (Nikon LaboPhot II equipped with a DS-Fi1 camera). Ultrathin sections were contrasted ( 25 minutes uranyl acetate, 5 minutes lead citrate) and subsequently viewed and photographed with a Zeiss EM 902 transmission electron microscope (Carl Zeiss, Oberkochen, Germany) equipped with a slow-scan CCD camera (TRS, Tröndle). Images were corrected for brightness and contrast in Adobe Photoshop CS4.

To quantify the total number of ORNs, we first calculated the area of both antennal nerves from the light microscopic sections of the antennae by tracing the outlines in Image (Fig. 1H). EM photographs at magnifications between $\times 4,400$ and $\times 12,000$ were used to count all individual ORNs on five randomly chosen areas of $80.2 \pm$ 46.2 (SD) $\mu \mathrm{m}^{2}$. ORNs were distinguished from other sensory neurons by their small diameter (Nishino et al., 2009). Total ORN number was then calculated by multiplying the mean ORN density of the five areas with the total antennal nerve cross-section area.

The only published ORN numbers for Apis are extrapolations derived from multiplication of sensilla numbers by mean receptor neuron number/sensillum ratios $(\mathrm{R} / \mathrm{S}$ ratio). Furthermore, estimates for drone antennae were obtained using worker R/S ratios (Esslen and Kaissling, 1976). For reliable comparisons, we therefore measured 
total ORN number also for workers and drones of Apis using the same procedure as for Eucera.

\section{Brain reconstruction}

Eucera and Apis specimens were cooled in a freezer for several minutes. The heads were removed with a sharp razor blade and mounted in wax dishes for preparation. The head capsule was opened, and the brain was dissected in ice-cold phosphate-buffered saline (PBS; pH 7.4). Brains were subsequently transferred to $4 \%$ paraformaldehyde in PBS and prefixed for 2 hours. The brains were then transferred to a second fixative (FixMix: 2\%
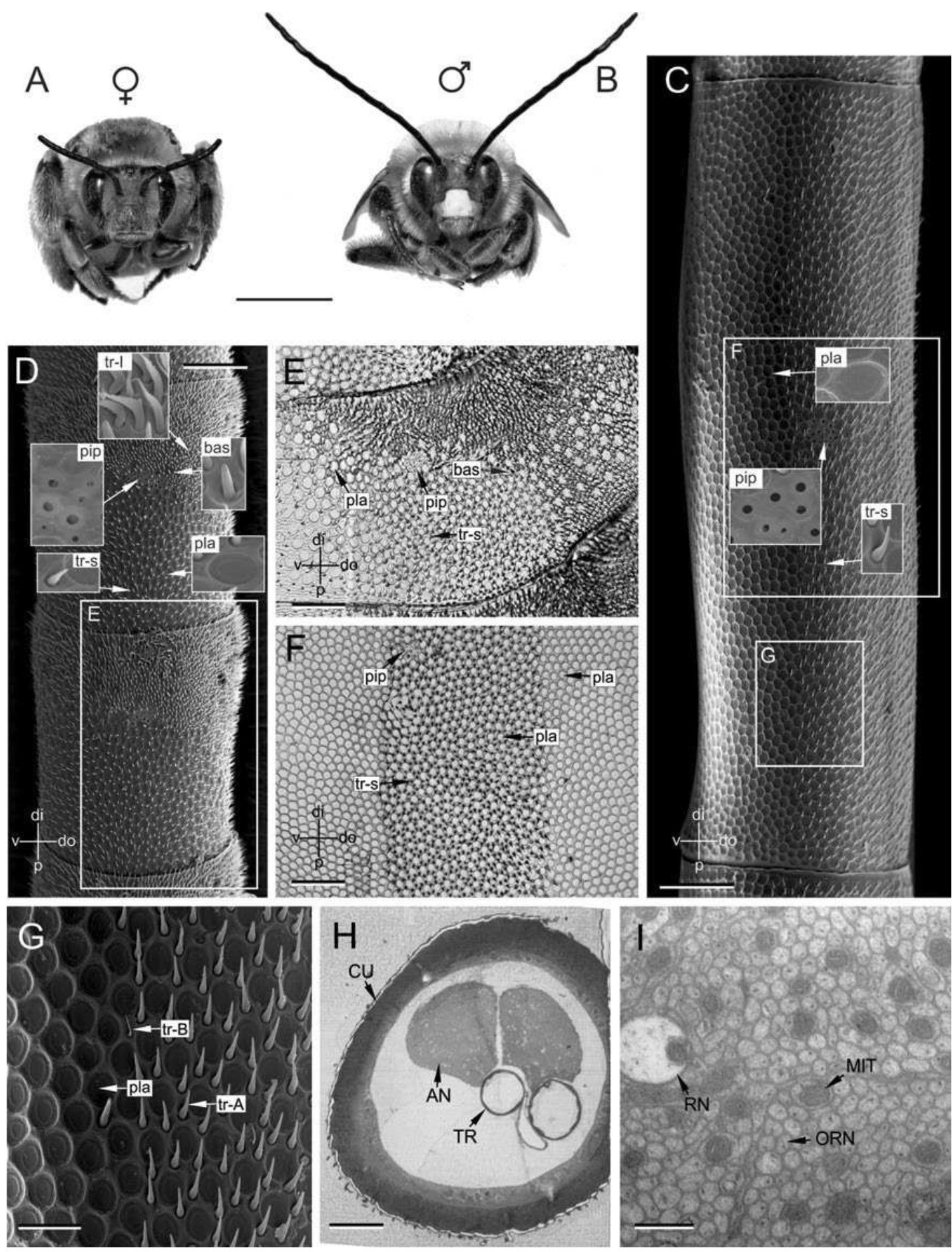

Figure 1 
paraformaldehyde, 2\% glutaraldehyde in PBS; Kuebler et al., 2010) and postfixed for several days at $4^{\circ} \mathrm{C}$. For confocal microscopy, the brains were first dehydrated in an ascending series of ethanol (50\%, 70\%, 90\%, 96\%, $3 \times$ $100 \%, 10$ minutes each) and subsequently transferred to methylsalicylate (M-2047; Sigma-Aldrich, Steinheim, Germany).

Whole brains were mounted in customized aluminum slides and scanned with a laser scanning confocal microscope (Leica TCS SP2 AOBS; Leica Microsystems AG, Wetzlar, Germany) equipped with an argon/krypton laser $\left(\lambda_{\mathrm{ex}}=561 \mathrm{~nm}\right)$. Appropriate objective lenses were used to scan brains (HC PL APO CS $10.0 \times 0.40 \mathrm{UV} ; 10.0 \times$ $0.40 \mathrm{IMM} / \mathrm{CORR})$ at intervals of $4-5 \mu \mathrm{m}$ and ALs $(10.0 \times$ 0.40 IMM/CORR, HC PL APO lbd.BL $20.0 \times 0.70$ IMM/ CORR UV) at $1 \mu \mathrm{m}$. z-Axis refractive index mismatches were corrected manually before 3-D reconstruction.

Reconstruction and volumetric analyses were carried out with Amira 3.1 (Mercury Computer Systems, Berlin, Germany). We reconstructed the neuropil volume (without cell bodies) of the third optic lobe neuropil, ALs, central complex, and MBs of 16 brains ( $E$. berlandi: females and males, $\mathrm{n}=4$ each; $A$. mellifera: workers and drones, $\mathrm{n}=4$ each). Because of the large size of the brains, only a part of the optical lobes could be scanned in most of the preparations. For our analysis, we therefore included only the third optical lobe neuropil, the lobula, which could be completely reconstructed in all preparations. As a measure of total brain size, we also reconstructed the remainder of the supraesophageal ganglion (SEG; excluding cell bodies) and calculated the sum of all reconstructed neuropils. To distinguish the SEG from the subesophageal ganglion, all neuropil located dorsal of the esophageal foramen was arbitrarily assigned to the SEG.
ALs of Eucera (females $n=3$, males $n=4$ ) were scanned at a higher magnification and reconstructed. All individual glomeruli were segmented and subsequently reconstructed in 3D. Volumetric data were calculated in Amira 3.1 and exported to Microsoft Excel 2007 (Microsoft Corporation, Redmond, WA) and SigmaPlot 11.0 (Systat Software, Chicago, IL) for further analysis. AL data for Apis were obtained from the literature (Arnold et al., 1985; Brockmann and Brückner, 2001). Previously published volume data on brain neuropils in Apis may not be comparable because of methodological differences (see comments in Fahrbach et al., 1995). We therefore decided to repeat brain neuropil measurements in Apis using the same method as for Eucera.

\section{Definition of a macroglomerulus}

Numerous studies reported the presence of conspicuously large glomeruli, so-called macroglomeruli (MG) or macroglomerular complexes (MGCs), and several measures are used to define an MG (Kelber et al., 2009; Kuebler et al., 2010). Here, we followed the definition by Kuebler et al. (2010), using descriptive statistics of the distribution of glomeruli volumes in each individual and treating all glomeruli as MGs that exceed the upper percentile by more than three times the interpercentile range (using the 10th and 90th percentile, i.e., the range that includes $80 \%$ of the measured values).

\section{Statistical analysis}

To compare absolute brain volume between sexes, a nonparametric Mann-Whitney U-test was applied. For comparison of the relative neuropil volumes, percentage values were first arcsine-transformed. All $P$ values below the $5 \%$ level were considered to be statistically

Figure 1. A,B: Dried specimens of Eucera berlandi illustrating the pronounced sexual dimorphism of the peripheral olfactory system. The male (B) antenna possesses about three times the surface area compared with the female (A). Scanning electron microscopic images $(C, D, G)$ and light microscopic images $(E, F)$ of replicas of the female $(C, E)$ and male $(C, F, G)$ antennal surface. The approximate regions of the details in E G are indicated by boxed areas in C,D. A variety of sensilla types is present on the antenna in both sexes. Pore plates (pla) were found on all flagellar segments except for the most proximal one. Their number is about 10 times higher in males compared with females. In males, poreplates are distributed almost uniformly over the antennal surface, whereas, in females, their distribution is patchy (C,D). Peg in pit sensilla (pip) are present as a single cluster with few individual sensilla outside the cluster. They could not be fur ther subclassified with the applied technique. Short trichoid sensilla were found in both sexes (tr s; C G). Higher magnifications (G) allows us to subclassify them into sensilla trichodea A (tr A; sensu Esslen and Kaissling, 1976) and sensilla trichodea B (tr B). They are located mainly in the PP rich region in females and form a conspicuous band along the anterior rim of the antenna in males. Longer trichoid sen silla ( $\operatorname{tr}$ I) are present in females but are lacking in males. Basiconic sensilla (bas) were found only on the female antenna (D,E) and are clearly lacking in males. $\mathrm{H}$ : Semithin section at the base of flagellum segment 1 of a male E. berlandi. The two antennal nerves (AN) are almost identical in cross section area. Two large tracheae (TR) are present in the antennal lumen. CU, cuticle. I: Transmission electron mi croscopic images of the antennal nerve. The antennal nerve tissue comprises mainly ORNs; other receptor neurons (RN) such as mechano, thermo, or hygrosensitive neurons are present at much lower numbers. Mitochondria (MIT) are also abundant in the antennal nerve. ORNs can be distinguished from other sensory neurons by their small diameter (Nishino et al., 2009). di, Distal; do, dorsal; p, proxi mal; v, ventral. All images were adjusted for brightness and contrast in Adobe Photoshop CS 4. The entomological pins were digitally removed from the images in A,B. Scale bars $5 \mathrm{~mm}$ in A,B; $100 \mu \mathrm{m}$ in C,D,F,G (20 $\mu \mathrm{m}$ for sensilla insets); $25 \mu \mathrm{m}$ in $\mathrm{E} ; 50 \mu \mathrm{m}$ in $\mathrm{H} ; 500$ $\mathrm{nm}$ in $\mathrm{I}$. 
TABLE 1.

Morphological Features of Antennae and Antennal Lobe of Eucera berlandi and Apis mellifera Males and Females ${ }^{1}$

\begin{tabular}{|c|c|c|c|c|}
\hline & \multicolumn{2}{|c|}{ Eucera berlandi } & \multicolumn{2}{|c|}{ Apis mellifera } \\
\hline & Female & Male & Worker & Drone \\
\hline Flagellum surface $\left(\mathrm{mm}^{2}\right)$ & $3.94(0.07) n$ & $15.38(0.45) n$ & $1.58^{2}$ & $3.55^{2}$ \\
\hline No. pore plates (per antenna) & $3,283 / 3,334 / 3,497$ & $34,604 / 36,769 / 35,362$ & $2,530 / 2,672^{2}$ & $18,153 / 19,035^{2}$ \\
\hline Pore plate dimensions $(\mu \mathrm{m})$ & $\begin{array}{c}15.7(2.0) \times 13.3(2.0) \\
n \quad 30\end{array}$ & $\begin{array}{c}15.4(1.2) \times 14.0(1.0) \\
n \quad 30\end{array}$ & $16 \times 9^{2}$ & $14 \times 9^{2}$ \\
\hline Antennal nerve area $\left(\mu \mathrm{m}^{2}\right)$ & 4,472 & $11,713 / 12,591$ & $4,393 / 5,268$ & 9,290 \\
\hline No. ORNs & 98,601 & $268,265 / 298,767$ & $73,309 / 99,332$ & 288,966 \\
\hline No. glomeruli & $132 / 133 / 133$ & $95 / 95 / 98 / 103$ & $\begin{array}{c}165 / 166 / 166 / \\
166 / 174^{3}\end{array}$ & $\begin{array}{c}102 / 102 / 104 / \\
104 / 104^{3}\end{array}$ \\
\hline No. MGs & 0 & 4 & $0^{3}$ & $4^{3}$ \\
\hline $\begin{array}{l}\text { Proportion MGs/glomerular } \\
\text { volume }\end{array}$ & & 0.360 .44 & & $0.44^{3}$ \\
\hline $\begin{array}{l}\text { Total glomerular } \\
\quad \text { volume }\left(\times 10^{3} \mu^{3}\right)\end{array}$ & $6.2(1.1)$ & $14.4(2.7)$ & & \\
\hline
\end{tabular}

${ }^{1}$ When means are presented, standard deviation is given in parentheses.

${ }^{2}$ From Esslen and Kaissling (1976).

${ }^{3}$ From Arnold et al. (1985).

significant. All statistical calculations were performed in SigmaPlot 11.0. For data visualization we used SigmaPlot 11.0 and Microsoft Excel 2007.

\section{RESULTS}

\section{Eucera berlandi Antennal morphology}

The antenna of Eucera consists of a scape, pedicel, and flagellum, which in males has 11 and in females 10 segments, a common trait in bees (Michener, 2007). The male flagellum is more than three times as long as the female flagellum ( $\mathrm{FL}_{\text {male }}: 12.1 \pm 0.1$ [SD] mm, and $\mathrm{FL}_{\text {fe- }}$ male: $3.7 \pm 0.2[S D] \mathrm{mm} ; \mathrm{n}=3$ each) and is about onethird wider in males $(0.45 \pm 0.00[S D] \mathrm{mm})$ than in females ( $0.34 \pm 0.02$ [SD] mm; $n=3$ each; Table 1$)$. The larger size in males results from one additional segment and overall elongated individual flagellum segments. Total surface area, measured from surface imprints, is $15.4 \pm$ 0.5 (SD) $\mathrm{mm}^{2}$ for the males, nearly four times the area of the female antenna $\left(3.9 \pm 0.1\right.$ [SD] $\mathrm{mm}^{2} ; \mathrm{n}=3$ each; Table 1). The male antenna appears dorsoventrally flattened, whereas the female antenna is round in crosssection.

\section{Sensilla types and distribution on the antenna}

Several types of sensilla are present on the antenna in both sexes (Fig. 1). We classified them based on their gross morphology into placoid, basiconic, trichoid, and peg-in-pit sensilla. The focus of our study was to assess the number of the main olfactory sensilla, the placoid sensilla (PPs); however, the presence and topography of the other types are described for both sexes in brief.

\section{Sensilla placodea}

The total number of PPs on each antenna is 35,578 \pm 1,099 for males and 3,371 \pm 112 for females (means \pm SD; $n=3$ each; Table 1). PPs are present on all flagellar segments, except for the most proximal segment, and their numbers vary between flagellar segments in both sexes. PP topography differs between sexes. In the female, patches of PPs are present at the anterior-distal part of each segment. Only few PPs are scattered throughout the rest of the segment (Fig. 1D,E). On the male antenna, PPs cover the whole antennal surface except for a small band on the posterior surface, which contains no sensilla at all. The posterior flagellum surface consists of very thick cuticle, which probably serves to increase stability during flight. Although the dorsal and ventral surfaces of the male antenna are exclusively equipped with PPs, the anterior surface shows a conspicuous band with a mixture of PPs and trichoid sensilla (see below; Fig. 1C,F,G). In males, the total PP density is between two and three times higher than in females $\left(2,289 \pm 58\right.$ and $856 \pm 38 \mathrm{PP} / \mathrm{mm}^{2}$ antennal surface, respectively; mean $\pm S D ; n=3$ each). Individual PPs measure $15.7 \pm 2.0 \times 13.3 \pm 2.0 \mu \mathrm{m}(\mathrm{n}=$ $30)$ in females $(n=1)$ and $15.4 \pm 1.2 \times 14.0 \pm 1.0 \mu \mathrm{m}(\mathrm{n}$ $=30)$ in males $(\mathrm{n}=1)$.

\section{Sensilla trichodea}

Trichoid sensilla occur on the antennal surface of both sexes. Two types of trichoid sensilla were distinguished. One type, short trichoid sensilla, is present on flagellar segments 3-10 in females and 2-11 in males. In females, this type is mainly located in the PP-rich region between the PPs and on the ventral surface of the antenna. In males, short trichoid sensilla are present only on the 
TABLE 2.

Sex-Specific Ratios of Selected Traits of the Olfactory Pathway of Eucera berlandi and Apis mellifera ${ }^{1}$

\begin{tabular}{lcc}
\hline & Eucera berlandi & Apis mellifera \\
\hline No. of PP sensilla (m:f) & 10.6 & $7.2^{2}$ \\
Antennal nerve area (m:f) & 2.7 & 1.9 \\
ORN number (m:f) & 2.9 & 3.3 \\
Rel. AL volume (m:f) & 1.6 & 0.9 \\
Rel. MB volume (m:f) & 0.9 & 0.7 \\
\hline
\end{tabular}

${ }^{1}$ Means were used to calculate ratios (Table 1). No statistical compari sons were performed. Relative volume of neuropils is calculated relative to total brain size. $m$, Male; $f$, female; PP, pore plates; ORN, olfactory receptor neuron; MB, mushroom body; AL, antennal lobe; Lo, lobulae.

${ }^{2}$ From Esslen and Kaissling (1976).

anterior rim of the antenna (except for a few single sensilla that are found outside this region), where they form a conspicuous band (Fig. 1D,G).

The second type, long trichoid sensilla, is present only on the female antenna. These sensilla are located primarily on flagellar segments 3-10 mainly distal and dorsal to the PP-rich region. In males, long trichoid sensilla are absent in the flagellum segments $2-11$. With the applied technique, they appear similar to long, stiff setae, which are located on the basal segments in males (flagellum segment 1) and females (flagellar segments 1-2), and thus the presence of long trichoid sensilla in these segments cannot be entirely excluded.

\section{Peg-in-pit sensilla}

Peg-in-pit sensilla are present on the antennal surface in both sexes. In both sexes, they are clustered as a single patch on each segment, and few single peg-in-pit sensilla are present outside this patch (Fig. 1C,D). In females, the patch is located distal to the PP-rich area, at the anterior antennal surface (Fig. 1C,F). In males, the patch is centered at the lower rim within the conspicuous band of trichoid sensilla (Fig. 1D,G). The three types of peg-in-pit sensilla (S. ampullaceum, S. coeloconicum, and S. coelocapitulum) are morphologically indistinguishable on the imprint and thus could not be further classified.

\section{Sensilla basiconica}

Basiconic sensilla occur only in females on flagellar segments 3-10. They are located mainly in the distal region of the anterior surface of each segment, scattered among trichoid sensilla (Fig. 1C,F). Their number was not assessed. In male $E$. berlandi, no basiconic sensilla are found on the antennal surface, a trait that seems to be common to male bees.

\section{Antennal nerve size and ORN numbers}

The receptor cell axons form two antennal nerves, which are almost identical with respect to their cross-

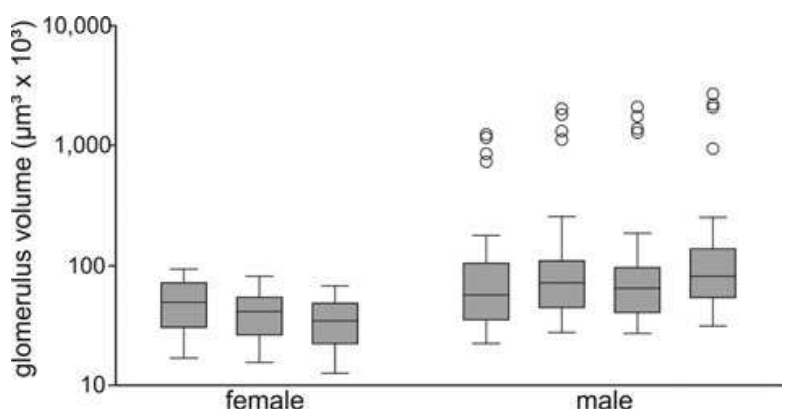

Figure 2. Glomeruli volume distribution in female (left) and male (right) Eucera berlandi. Males exhibit extremely enlarged glomeruli (macroglomeruli, MGs; open circles), which are defined as outliers exceeding three times the interpercentile range (10th and 90th percentile) from the upper percentile. In females, no MGs are found, whereas all males possess four MGs. The total number of glomeruli is higher in females (132 133, see Results and Table 1) than in males (95 103). Note that the y axis is scaled logarithmi cally, so the difference between median and MGs is greater than it appears. Lines represent the median, boxes the upper and lower quartiles, and the whiskers the 10th and 90th percentiles.

sectional area. The cross-sectional area of the antennal nerve in male $E$. berlandi is $12,152 \pm 621 \mu \mathrm{m}^{2}$ (mean \pm $\mathrm{SD} ; \mathrm{n}=2$ ), almost three times the area of the female $\left(4,472 \mu \mathrm{m}^{2} ; \mathrm{n}=1\right.$; Tables 1,2$)$. The calculated number of ORNs per antenna is about three times higher in males (298,767 and 268,265 ORNs/antenna) than in females (98,601 ORNs/antenna). We additionally measured ORN diameters in all preparations. We found variation (range of means $121-173 \mathrm{~nm}, \mathrm{n}=50$ per individual); however, it is not clear whether these differences reflect variation between sexes and/or individuals. Additional measurements on a larger sample are therefore needed to elucidate the source of this variation.

\section{AL morphology}

The antennal nerves terminate in the $\mathrm{AL}$, where ORNs are sorted and converge onto glomeruli. The number of glomeruli is $\sim 26 \%$ (35 glomeruli) lower in males $(95,96$, $98,103)$ compared with females $(132,133,133$; Table 1). For the male $A L$, we found four strikingly large glomeruli that, according to our definition, are to be considered as macroglomeruli (MG; Figs. 2, 3A,B). Two of the MGs are located at the anterior side of the $A L$ near the entrance of the antennal nerve. The other two MGs are located at the posterior part of the AL (Fig. 3B). We termed them MG 1-4, with MG 1 lying anterior and proximal, MG 2 anterior and distal, MG 3 posterior and proximal, and MG 4 posterior and distal from the antennal nerve entrance (Fig. 3A,B). The volume of the four MGs accounts for $36-44 \%$ of total glomerular volume (Table 1). The largest glomeruli are MG 2 and MG 4; they 


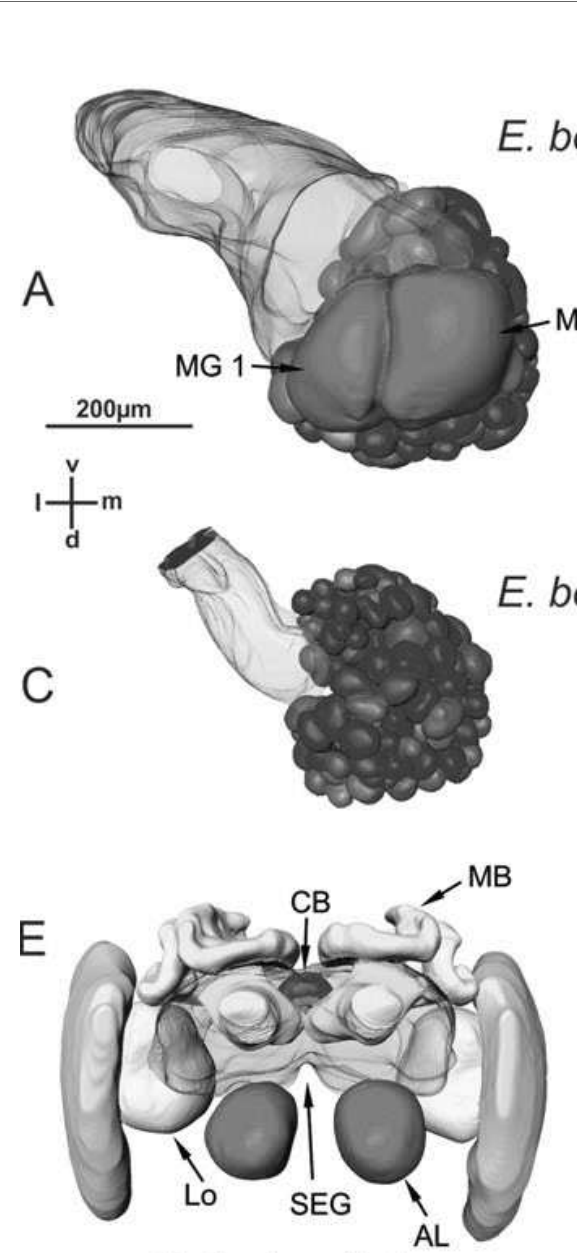

E. berlandi $0^{*}$

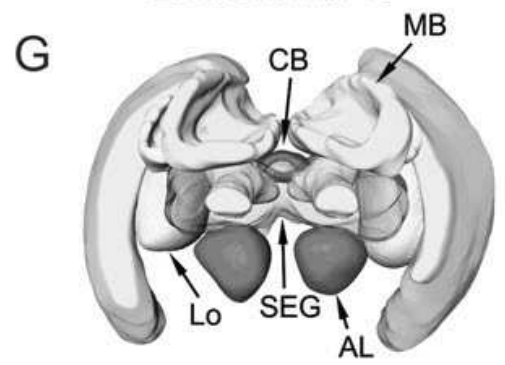

A. mellifera o"

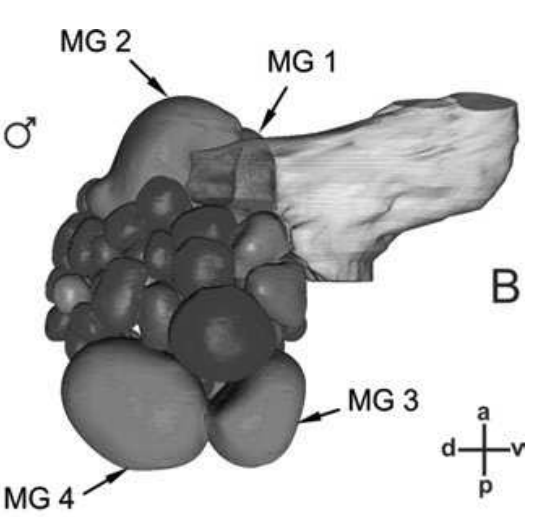

$\underline{200 \mu \mathrm{m}}$

\section{berlandi $\$$}
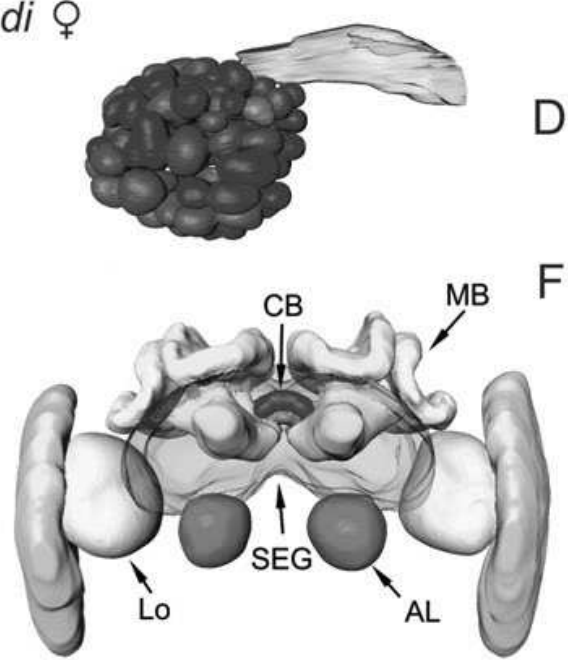

E. berlandi 우

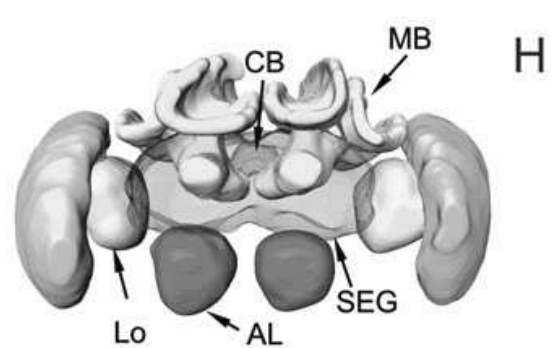

A. mellifera Ø̧

Figure 3. $3 \mathrm{D}$ reconstruction of the antennal lobes (ALs) and whole brains of Eucera berlandi males and females and Apis mellifera drones and workers. A,B: $3 \mathrm{D}$ reconstruction of the glomeruli of the (left) AL of a male E. berlandi viewed from anterior (A) and lateral (B). The four enlarged macroglomeruli (MGs) are depicted in red; all other glomeruli are shown in blue. MG 1 and MG 2 lie at the anterior part of the antennal lobe, whereas MG 3 and MG 4 are located at the posterior part. The largest glomeruli are MG 2 and MG 4. C,D: 3 D recon struction of the glomeruli in the (left) antennal lobe of a female $E$. berlandi (C, anterior view; E, lateral view). No enlarged glomeruli are present. The antennal nerve is depicted as transparent in all views. The nerve is larger in diameter in males compared with females, a result of the higher number of ORNs. E,F: 3 D reconstruction of selected neuropils of the brain in male and female $E$. berlandi. Lo, lobula; $\mathrm{CB}$, central body; MB, mushroom bodies; SEG, remainder of the supraesophageal ganglion. The medulla is depicted for visualization only but not included in the analysis. G,H: 3 D reconstruction of selected neuropils of drone and worker honeybees. a, Anterior; d, dorsal; I, lat eral; m, median; p, posterior; v, ventral. Scale bars $200 \mu \mathrm{m}$ in A (applies to A,C); $200 \mu \mathrm{m}$ in B (applies to B,D); $500 \mu \mathrm{m}$ in H (applies to E H). 

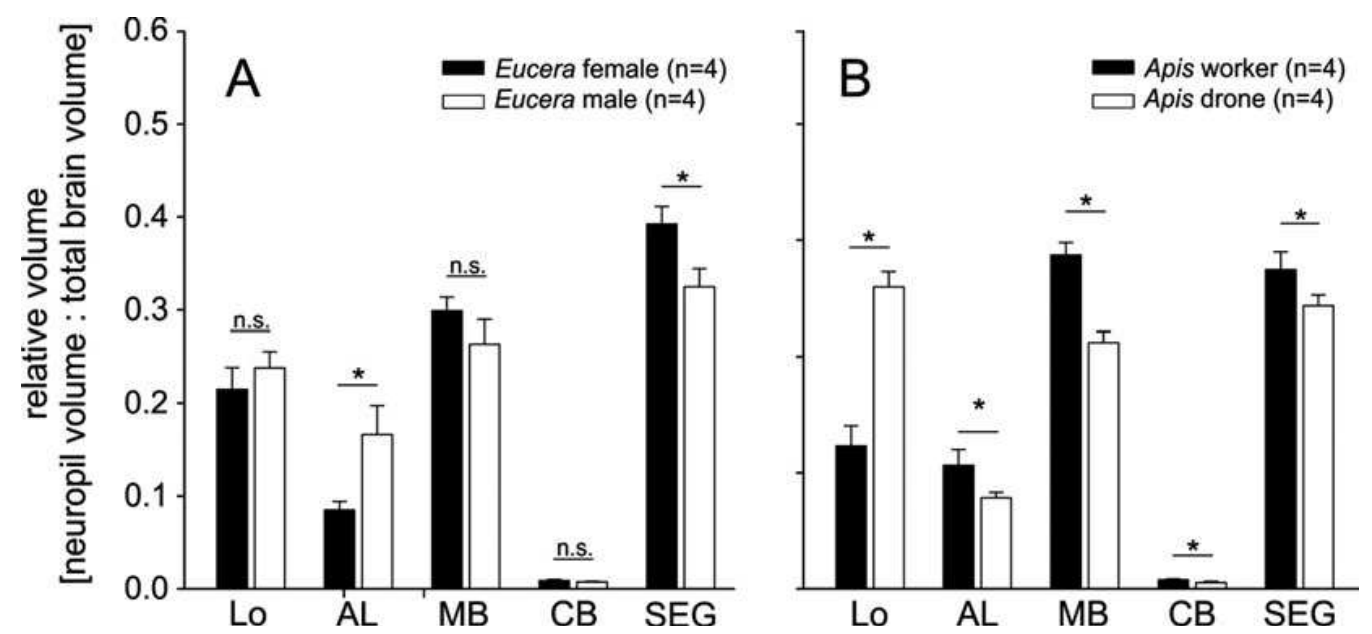

Figure 4. Comparison of relative neuropil volumes in Eucera (A) and Apis (B). All neuropil volumes were calculated relative to total brain volume (sum of all neuropils). Lo, lobulae; AL, antennal lobes; MB, mushroom bodies; CB, central body; SEG, remainder of the supraeso phageal ganglion. Bars represent means \pm SD (n 4 each). Relative volume differences were compared between sexes using a nonpara metric Mann Whitney $U$ test after arcsine transformation of percentage values; n.s., $P>0.05 ;{ }^{\star} P<0.05$.

are between 20 and 32 times larger than the median glomerulus volume. In two preparations, the frontal MG 2 was found to be the largest MG; in two other preparations, the anterior MG 4 was the largest. MG 1 and MG 3 are smaller, with MG 1 being the larger of the two in three of four preparations. MG 1 and MG 3 are between 11 and 25 times the volume of the median glomerulus. In comparison, only regularly sized glomeruli are present in the female $\mathrm{AL}$, with the largest glomerulus having five to six times the volume of the median ( $n=3$; Figs. 2, 3D,E). Glomeruli volumes are not normally distributed in all prep-

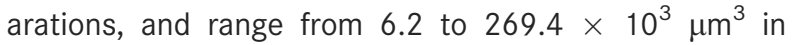
females (medians $34.5,41.4,49.3 \mu \mathrm{m}^{3} ; \mathrm{n}=3$ ) and from 7.5 to $2,677.1 \times 10^{3} \mu^{3}$ (medians 56.9, 64.6, 71.9, $\left.81.7 \mu \mathrm{m}^{3} ; \mathrm{n}=4\right)$ in males. The total glomerular volume in males is more than twice that of females.

\section{Selected brain neuropils}

3-D reconstructions of male and female brains allowed volumetric comparison of selected neuropils. As a measure of total brain size, we calculated the sum volume of all reconstructed neuropils. In Eucera, brain volume differs significantly between sexes and is larger in females (Vol female: $401.5 \pm 29.3$ [SD] $\mu \mathrm{m}^{3}$, Vol male $368.6 \pm 42.7$ [SD] $\mu \mathrm{m}^{3} ; \mathrm{n}=4$ each; $P<0.05$, Mann-Whitney U-test). Among the individual neuropils, only the ALs and the remainder of the supraesophageal ganglion (SEG) differ significantly in their relative volume. While the ALs are larger in males (13\% of total brain volume compared with $8 \%$ in females), the SEG is larger in females (Fig. 4). The MBs account for $30 \%$ of the total brain volume in females and $26 \%$ in males.

\section{Apis mellifera \\ Antennal nerve size and ORN numbers}

The antennal nerve cross-sectional area of $A$. mellifera drones is $9,290 \mu \mathrm{m}^{2}(\mathrm{n}=1)$, about twice that of the workers $(4,831 \pm 619$ [SD] $\mu \mathrm{m} ; \mathrm{n}=2$; Tables 1,2$)$. The number of ORNs per antenna in drones (288,966 ORNs / antenna, $\mathrm{n}=1$ ) is about three times higher compared with workers (99,332 and 73,309 ORNs/antenna; $n=2$; Table 2). As in Eucera, ORN diameters vary between samples (range of means $115-150 \mathrm{~nm} ; \mathrm{n}=50$ per individual), without a clear caste-specific separation (see above).

\section{Selected neuropils}

In Apis, absolute brain volume is significantly larger in drones compared with workers (Vol worker: $_{209.7 \pm 21.4}$ [SD] $\mu^{3}{ }^{3}$ Vol $_{\text {drone: }} 220.1 \pm 15.4$ [SD] $\mu \mathrm{m}^{3} ; \mathrm{n}=4$ each; $P$ $<0.05$, Mann-Whitney U-test). All neuropils differ in their relative size between sexes. The lobulae occupy about twice the relative volume in drones, but all other investigated neuropils were relatively smaller than in workers. The ALs cover $\sim 13 \%$ of the brain volume in workers and $10 \%$ in drones, and the MBs account for $36 \%$ of the brain volume in workers, compared with only $27 \%$ in drones.

\section{DISCUSSION}

We investigated the peripheral olfactory system and associated neuronal brain structures of the highly sexually dimorphic solitary bee species Eucera berlandi and compared it with the well-described olfactory system of Apis mellifera. Extreme sex differences in the size and sensillar equipment of the antennae (e.g., Eucera males 
have 10 times more PPs), total ORN number (males have three times more ORNs), and the presence of four macroglomeruli in the Eucera male AL suggest that high sensitivity for a few selected substances are of great importance for mate detection in E. berlandi. Although the extent of dimorphism in the periphery resembles or even exceeds that described for Apis, the relative investment in higher order processing neuropils was found to be not significantly different between sexes in Eucera, which contrasts with the condition observed in Apis.

We initially speculated that Eucera males are restricted in the allocation of neural resources for mate detection, whereas honeybee drones can afford a higher degree of specialization because of reduced natural selection associated with the safety provided by their colony. The supporting and opposing evidence regarding these predictions is discussed in more detail in the following.

\section{Origin of highly modified male sensory systems}

The origin of highly modified male sensory systems and sexual dimorphism in insects is considered to be driven by sexual selection (Allen et al., 2011; Andersson and Iwasa, 1996). Males compete for access to receptive females, and adaptations are favored that increase the chance of successful mating. Sexual selection is assumed to both counter and interact with natural selection (Allen et al., 2011; Andersson and Iwasa, 1996). Accordingly, male insects often invest more in improved, sex-biased sensory systems (Hansson and Stensmyr, 2011), but the elaboration of a biased sensory system is assumed to be limited (Andersson and Iwasa, 1996; Knell et al., 2004). Apis and Eucera males both certainly face strong malemale competition (Alcock et al., 1978; Danesch and Danesch, 1976; Shimron and Hefetz, 1985; Winston, 1991; and our observations); however, measuring the absolute strength of sexual selection is impossible, and our knowledge on the behavioral repertoire of males in solitary bees, and even in the well-investigated honeybee, is very limited (Ohtani, 1974).

\section{Sex specific adaptations of the antenna}

Our investigations of antennal parameters in Eucera show a multiplication of PP sensilla and ORNs in males, illustrating the importance of olfactory sensing in mate detection (Tables 1, 2; Esslen and Kaissling, 1976). Such multiplications increase the likelihood of detecting odor molecules, lowering the detection threshold of the antenna. Eucera males seem to invest more in olfactory sensing than Apis drones, which is suggested by the longer antennae and higher sensilla numbers. Nonetheless, males of both species have very similar numbers of ORNs
(Table 1). In honeybees, individual PPs are innervated by 15-30 individual ORNs (Esslen and Kaissling, 1976; Kelber et al., 2006). Based on total ORN numbers divided by the number of PPs in Eucera, PPs are innervated by $\sim 29$ ORNs in females and $\sim 8$ in males. These numbers probably overestimate the actual numbers of ORNs per individual PP, because the contributions of other sensilla types to the total ORN number were ignored. However, our results illustrate that, in Eucera males, PPs are innervated by fewer (less than half as many) ORNs compared with the PPs of Apis drones (Esslen and Kaissling, 1976). To accommodate the $\sim 300,000$ ORNs found in males of both species, the antennae in Eucera must be equipped with twice as many PPs and are almost three times as long as in Apis drones. The long antennae likely produce considerable costs associated with development (Emlen, 2001), energy consumption (Chittka and Niven, 2009), and locomotion/aerodynamic drag (Swallow et al., 2000). On the other hand, long antennae increase the detection range for simultaneous odor tracking and may thus improve the detection of the female. A similar tradeoff has been described for Lepidoptera. Symonds et al. (2012) found antennal length to be negatively correlated with male abundance and molecular weight of the sex pheromone, suggesting a role of both detection range and chemical structure of the pheromone in the evolution of elongated antennae. At the present stage, the specific adaptive value of the long antennae is still unclear; they could be adaptations to the chemical structure of the sex pheromone, adaptations for elaborated orientation tasks, or merely a byproduct of a phylogenic constraint associated with the increase of ORN numbers and thus antennal sensitivity in Eucera males.

In Eucera females, PP and ORN numbers are comparable to the numbers found in Apis workers (Esslen and Kaissling, 1976; this study). Although the exact contribution of each sensillum type to total ORN number is unknown for Eucera, we suppose that PPs possess multiple ORNs in both sexes. Multiple ORNs are a common trait in Hymenoptera, but the role of this organizational principle is unknown (Kelber et al., 2006; Kleineidam and Rössler, 2009).

Aside from PPs we found high numbers of trichoid sensilla in both sexes. The short trichoid sensilla appear similar to Sensilla trichodea $\mathrm{A}$ and $\mathrm{B}$ of $A$. mellifera workers and drones (Fig. 1D,F,G; Esslen and Kaissling, 1976). Their function is unclear, but at least $\mathrm{S}$. trichodea $\mathrm{A}$ (one class of short trichoid sensilla) is assumed to sense odors (Esslen and Kaissling, 1976). Peg-in-pit sensilla have been shown to be thermo-, hygro-, and $\mathrm{CO}_{2}$-sensitive (Kleineidam et al., 2000; Lacher, 1964; Ruchty et al., 2009) and were found in both sexes in Apis (Nishino et al., 2009) and Eucera (this study). Sensilla basiconica 
were found only in females and were entirely absent in males. This sensilla type is also female specific in other Hymenoptera (Ågren, 1977, 1978; Ågren and Hallberg, 1996; Esslen and Kaissling, 1976; Mysore et al., 2010; Nakanishi et al., 2009; Nishino et al., 2009). A role in gustatory and olfactory chemoreception of colony-specific cuticular hydrocarbon profiles has been proposed for $\mathrm{S}$. basiconica, but conclusive studies on their function are still lacking (Ozaki et al., 2005; but see Brandstaetter and Kleineidam, 2011). S. basiconica innervate glomeruli clusters in the female $A L$ that are lacking in male ants (Kelber et al., 2010; Nakanishi et al., 2010) and bees (Nishino et al., 2009) and thus may contribute to the marked sexual dimorphism of glomeruli numbers observed in Hymenoptera (Schachtner et al., 2005).

\section{AL morphology}

Sex-specific adaptations of the ALs have been described for many insect species (Hansson and Stensmyr, 2011). Sex differences regard mostly the size of individual glomeruli, whereas numerical differences in glomeruli number are rare, with the exception of Hymenoptera (Schachtner et al., 2005; Strausfeld and Reisenman, 2009). The number of associated olfactory-guided behaviors, e.g., detection and discrimination of suitable larval nutrition, seeking nest sites, nest recognition, evaluation of brood viability, and in the case of social Hymenoptera intraspecific communication, may relate to the typically high number of glomeruli in Hymenoptera (Kleineidam and Rössler, 2009; Schachtner et al., 2005). The elaborate brood care performed by females, but not males, has been proposed to be a key factor for the evolution of the pronounced sexual dimorphisms (Stubblefield and Seger, 1994). Hymenopteran males usually have fewer glomeruli than females, indicating that lower numbers of functional receptor types are expressed in the antenna. The lower number theoretically reduces the dimensionality of odor coding and thus complexity of the male odor space. We found about 34 (26\%) fewer glomeruli in Eucera males, so glomeruli numbers are more similar between sexes compared with Apis ( $\sim 64-69$ or $\sim 38-$ $40 \%$ fewer glomeruli in males than in workers and $\sim 52-$ 62 or $\sim 33-38 \%$ less than in queens [Arnold et al., 1985, 1988; Groh and Rössler, 2008]). Compared with Apis, similar or even greater sex-specific differences in glomeruli number have been described for other eusocial insects (Kuebler et al., 2010; Mysore et al., 2009; Nishikawa et al., 2008; Stieb et al., 2011; Zube and Rössler, 2008) and reach up to $60 \%$ in the ant Harpegnathos saltator (Hoyer et al., 2005). In most eusocial species, males are embedded in a protective social network and leave the colony only for short, synchronized mating flights (Ayasse et al., 2001). The solitary life style of Eucera males likely imposes higher demands on orientation, food detection and sheltering, which distinguishes them from eusocial species and may have resulted in the evolution of relatively more complex (or less reduced) olfactory systems. Preliminary data from another solitary bee species further support our interpretation. Andrena nigroaenea males have $\sim 23 \%$ fewer glomeruli than females (M.S., unpublished data).

Alternatively, it can be argued that the larger sex differences and high numbers of glomeruli in honeybee workers and other eusocial Hymenoptera result from an increased demand for olfactory communication within the colony and are thus specific adaptations of the worker caste in eusocial Hymenoptera. Within bees, however, Apis worker do not have particularly many glomeruli, compared with other social and solitary species (M.S. and C.K., unpublished data).

\section{MGs}

The high sensitivity of honeybee drone antenna for the sex pheromone compound 9-ODA is considered to be the result of multiplication of PPs and a sex bias in the equipment with different receptor types. In Apis, the presence of four hypertrophied glomeruli coincides with the highly male-biased expression of four receptor genes, and for one of them the odor specificity has been demonstrated (Arnold et al., 1985; Sandoz, 2006; Wanner et al., 2007). In Eucera males, the presence of four MGs, occupying about $40 \%$ of the total glomerular volume, suggests a male bias in the equipment with corresponding receptor types, analogous to Apis drones. The involvement of the MGs in long distance sex pheromone detection is likely, and some evidence indicates the presence of long-distance attractants in Eucera (Priesner, 1973; and personal observations by M.S. and J.S.). Whether the putative pheromone receptors in Eucera are sex-specific receptor types, as in some moth species, or result from male-biased expression of a shared receptor type, as in Apis, remains to be investigated (Galizia and Rössler, 2010).

Additional chemical signals play an important role in close-range communication in $A$. mellifera mating behavior (Brockmann et al., 2006; Renner and Vierling, 1977), and previous studies suggest the involvement of "ordinary" glomeruli rather than MGs in processing these close-range substances (Brockmann et al., 1998; Sandoz, 2006). Evidence is still lacking that all MGs are involved in sex pheromone processing, and, as yet, the function of three of the four MGs in Apis remains unknown (Sandoz, 2006). In Eucera, the chemistry of sex communication has not yet been investigated. The exploitation of males by sexually deceptive orchids for the purpose of pollination (Streinzer et al., 2009) will facilitate future characterization of the behaviorally relevant pheromone 
components and thus evaluation of the role of MGs and ordinary glomeruli in mate detection.

\section{Higher processing centers in the brain}

In the insect brain, sensory input is processed in distinct modality-specific primary and integrative higher order neuropils (Strausfeld et al., 1998). Although recent studies challenge the use of absolute brain size as an estimator for behavioral complexity and computational power (Chittka and Niven, 2009, and references therein), many studies have shown correlations between brain size and performance (Deaner et al., 2007; Gronenberg and Couvillon, 2010; Lefebvre and Sol, 2008). Among related species and between sexes, comparisons of the relative size of brain regions are commonly used to quantify differential investment in brain tissue (Ehmer and Gronenberg, 2004; El Jundi et al., 2009; Ott and Rogers, 2010).

In Eucera males, relatively more neural tissue is devoted to the $A L$ than in females, underpinning the importance of this modality in mate detection (Table 2, Fig. 4). In Apis, the ALs are relatively smaller in males. In contrast, the lobulae are relatively larger, suggesting differences in the relative importance of vision vs. olfaction between the two species (Gronenberg and Hölldobler, 1999).

The MBs are considered as centers of multimodal integration and memory. They have been shown to be relatively larger in generalist feeders (Farris and Roberts, 2005; Ott and Rogers, 2010) and socially dominant caste members (Molina and O’Donnell, 2007). Larger MBs are assumed to reflect behavioral repertoire rather than social organization per se (Farris, 2005; Gronenberg, 2009; Smith et al., 2010). Sexual dimorphism in MB size is observed in many Hymenoptera (Ehmer and Gronenberg, 2004; Kuebler et al., 2010; Mysore et al., 2009) but not in other insect taxa (Dreyer et al., 2010; El Jundi et al., 2009). The observed sexual dimorphism in hymenopteran MBs probably illustrates the striking differences in ecology and life history. The reduced relative MB volume correlates with the probably smaller and less plastic behavioral repertoire in males (Ehmer and Gronenberg, 2004; Ohtani, 1974).

Consistent with our original interpretation, investment in $\mathrm{MB}$ tissue is more similar between sexes in Eucera compared with Apis. Males of the latter species have smaller MBs, which possibly reflects the relaxed natural selection pressure in conjunction with a more stereotyped mating behavior in honeybee drones, compared with Eucera males (Ohtani, 1974; Shimron and Hefetz, 1985; Winston, 1991). Further support comes from another solitary bee species, $A$. nigroaenea, which also shows no difference in relative MB investment (M.S., unpublished data). Alternatively, the larger MBs of honey- bee workers, relative to Apis drones and both Eucera sexes, may illustrate the demands for higher behavioral repertoires in workers of eusocial species compared with solitary species of bees (Smith et al., 2010).

\section{CONCLUSIONS AND FUTURE PERSPECTIVE}

In this study, we document the extraordinary sexual dimorphism of the olfactory system in a solitary bee species. We found a high degree of dimorphism at the periphery and in first-order neuropils. Surprisingly, the sexual dimorphism is not as pronounced in the central brain of Eucera. In comparison, the sexual dimorphism in Apis at the periphery is comparable to that of Eucera, and it is present along the entire olfactory pathway. In Apis drones, a stronger reduction in glomerular numbers and less investment in MB tissue was found compared with Eucera drones.

We initially expected, based on differences in the life style of males, that sexual dimorphism and allocation of brain resources to mating-related behaviors should be less elaborate in Eucera males than in Apis drones. Our findings support our prediction; however, alternative explanations limit our conclusions drawn from the observed differences between only two species of Hymenoptera.

Further studies, using an approach comparable to that in our investigation, are necessary to understand better the origin and extent of male-specific adaptations in bees. We suggest comparative sampling across the various families of bees, including species with various mating strategies and life styles. In particular, taxa that differ with respect to male ecology but not social structure are of great interest, because this allows one to separate male- and female-specific adaptations better. Bumblebees (Bombus) constitute good candidates. They show a eusocial life style, but males lack a colony support and have to forage for food and shelter by themselves (as with Eucera males).

\section{ACKNOWLEDGMENTS}

We thank M. Eberhard and J. Bauder for help with histological procedures, J. Plant for linguistic improvements, and the anonymous reviewers for their helpful comments. We further thank the Core Facility for Cell Imaging and Ultrastructural Research, University of Vienna, for providing facilities and support.

\section{CONFLICT OF INTEREST STATEMENT}

The authors declare no conflicts of interest. 


\section{ROLE OF AUTHORS}

All authors read and approved the final manuscript. Study concept and design: MS, CJK, JS. Acquisition of data: MS, CK, SP. Analysis and interpretation of data: MS, CJK, JS. Statistical analysis: MS; Drafting of the manuscript: MS, CJK, JS.

\section{LITERATURE CITED}

Alcock J, Barrows EM, Gordh G, Hubbard LJ, Kirkendall L, Pyle DW, Ponder TL, Zalom FG. 1978. Ecology and evolution of male reproductive behavior in the bees and wasps. Zool J Linn Soc 64:293 326.

Allen CE, Zwaan BJ, Brakefield PM. 2011. Evolution of sexual dimorphism in the Lepidoptera. Annu Rev Entomol 56: 445464.

Andersson M, Iwasa Y. 1996. Sexual selection. Trends Ecol Evol 11:53 58

Arnold G, Masson C, Budharugsa S. 1985. Comparative study of the antennal lobes and their afferent pathway in the worker bee and the drone (Apis mellifera). Cell Tissue Res 242:593 605.

Arnold G, Budharugsa S, Masson C. 1988. Organization of the antennal lobe in the queen honey bee, Apis mellifera $\mathrm{L}$ (Hymenoptera, Apidae). Int J Insect Morphol Embryol 17: 185195.

Ågren L. 1977. Flagellar sensilla of some Colletidae (Hymenop tera: Apoidea). Int J Insect Morphol Embryol 6:137 146.

Ågren L. 1978. Flagellar sensilla of two species of Andrena (Hymenoptera: Andrenidae). Int J Insect Morphol Embryol 7:73 79.

Ågren L, Hallberg E. 1996. Flagellar sensilla of bumble bee males (Hymenoptera, Apidae, Bombus). Apidologie 27:433 444.

Ayasse M, Paxton RJ, Tengo J. 2001. Mating behavior and chemical communication in the order Hymenoptera. Annu Rev Entomol 46:31 78.

Boeckh J, Tolbert LP. 1993. Synaptic organization and devel opment of the antennal lobe in insects. Microsc Res Tech niq 24:260 280 .

Brandstaetter AS, Kleineidam CJ. 2011. Distributed represen tation of social odors indicates parallel processing in the antennal lobe of ants. J Neurophysiol 106:2437 2449.

Brockmann A, Brückner D. 2001. Structural differences in the drone olfactory system of two phylogenetically distant Apis species, A. florea and A. mellifera. Naturwissenschaften 88:78 81.

Brockmann A, Brückner D, Crewe RM. 1998. The EAG response spectra of workers and drones to queen honey bee mandibular gland components: the evolution of a social signal. Naturwissenschaften 85:283 285.

Brockmann A, Dietz D, Spaethe J, Tautz J. 2006. Beyond 9 ODA: sex pheromone communication in the European honey bee Apis mellifera L. J Chem Ecol 32:657 667.

Chittka L, Niven J. 2009. Are bigger brains better? Curr Biol 19:R995 R1008.

Danesch E, Danesch O. 1976. Zur Ethologie von Eucera taur ica MOR. (Insecta: Hymenoptera, Apidae). Ber Nat Med Ver Innsbruck 63:231 244.

de Bruyne M, Baker TC. 2008. Odor detection in insects: vola tile codes. J Chem Ecol 34:882 897.

Deaner RO, Isler K, Burkart J, van Schaik C. 2007. Overall brain size, and not encephalization quotient, best predicts cognitive ability across non human primates. Brain Behav Evol 70:115 124.

Dreyer D, Vitt H, Dippel S, Goetz B, El Jundi B, Kollmann M, Huetteroth W, Schachtner J. 2010. 3D standard brain of the red flour beetle Tribolium castaneum: a tool to study metamorphic development and adult plasticity. Front Syst Neurosci 4:3.

Ehmer B, Gronenberg W. 2004. Mushroom body volumes and visual interneurons in ants: comparison between sexes and castes. J Comp Neurol 469:198 213.

El Jundi B, Huetteroth W, Kurylas AE, Schachtner J. 2009. Ani sometric brain dimorphism revisited: Implementation of a volumetric 3D standard brain in Manduca sexta. J Comp Neurol 517:210 225.

Emlen DJ. 2001. Costs and the diversification of exaggerated animal structures. Science 291:1534 1536.

Esslen J, Kaissling KE. 1976. Zahl und Verteilung antennaler Sensillen bei der Honigbiene (Apis mellifera L.). Zoomor phology 83:227 251.

Fahrbach SE, Giray T, Robinson GE. 1995. Volume change in the mushroom bodies of adult honey bee queens. Neuro biol Learn Mem 63:181 191.

Fahrbach SE, Giray T, Farris SM, Robinson GE. 1997. Expan sion of the neuropil of the mushroom bodies in male honey bees is coincident with initiation of flight. Neurosci Lett 236:135 138.

Farris S. 2005. Evolution of insect mushroom bodies: old clues, new insights. Arthropod Struct Dev 34:211 234.

Farris SM, Roberts NS. 2005. Coevolution of generalist feed ing ecologies and gyrencephalic mushroom bodies in insects. Proc Natl Acad Sci U S A 102:17394 17399.

Galizia CG, Rössler W. 2010. Parallel olfactory systems in insects: anatomy and function. Annu Rev Entomol 55:399 420.

Groh C, Rössler W. 2008. Caste specific postembryonic devel opment of primary and secondary olfactory centers in the female honeybee brain. Arthropod Struct Dev 37:459 468.

Gronenberg W. 2008. Structure and function of ant (Hyme noptera: Formicidae) brains: strength in numbers. Myrme col News 11:25 36.

Gronenberg WR. 2009. Social brains and behavior past and present. In: Gadau J, Fewell J, Wilson ED, editors. Organiza tion of insect societies: from genome to sociocomplexity. Cambridge, MA: Harvard University Press.

Gronenberg W, Couvillon MJ. 2010. Brain composition and ol factory learning in honey bees. Neurobiol Learn Mem 93: 435443.

Gronenberg W, Hölldobler B. 1999. Morphologic representa tion of visual and antennal information in the ant brain. J Comp Neurol 412:229 240.

Hansson BS, Stensmyr MC. 2011. Evolution of insect olfac tion. Neuron 72:698 711 .

Hoyer SC, Liebig J, Rössler W. 2005. Biogenic amines in the ponerine ant Harpegnathos saltator: serotonin and dopa mine immunoreactivity in the brain. Arthropod Struct Dev 34:429 440.

Kaissling KE, Renner M. 1968. Antennale Rezeptoren für Queen Substance und Sterzelduft bei der Honigbiene. Z Vergl Physiol 59:357 361.

Kelber C, Rössler W, Kleineidam CJ. 2006. Multiple olfactory receptor neurons and their axonal projections in the anten nal lobe of the honeybee Apis mellifera. J Comp Neurol 496:395 405.

Kelber C, Rössler W, Roces F, Kleineidam CJ. 2009. The anten nal lobes of fungus growing ants (Attini): neuroanatomical traits and evolutionary trends. Brain Behav Evol 73:273 284.

Kelber C, Rössler W, Kleineidam CJ. 2010. Phenotypic plastic ity in number of glomeruli and sensory innervation of the antennal lobe in leaf cutting ant workers (A. vollenweideri). Dev Neurobiol 70:222 234

Kleineidam CJ, Rössler W. 2009. Adaptations in the olfactory system of social Hymenoptera. In: Gadau J, Fewell J, Wil son E, editors. Organization of insect societies: from 
genome to sociocomplexity. Cambridge, MA: Harvard Uni versity Press.

Kleineidam C, Romani R, Tautz J, Isidoro N. 2000. Ultrastruc ture and physiology of the $\mathrm{CO}_{2}$ sensitive sensillum ampul laceum in the leaf cutting ant Atta sexdens. Arthropod Struct Dev 29:43 55.

Knell RJ, Pomfret JC, Tomkins JL. 2004. The limits of elabora tion: curved allometries reveal the constraints on mandible size in stag beetles. Proc Biol Sci 271:523 528.

Kuebler LS, Kelber C, Kleineidam CJ. 2010. Distinct antennal lobe phenotypes in the leaf cutting ant (Atta vollenweideri). J Comp Neurol 518:352 365.

Lacher V. 1964. Elektrophysiologische Untersuchungen an einzelnen Rezeptoren für Geruch, Kohlendioxyd, Luftfeuch tigkeit und Temperatur auf den Antennen der Arbeitsbiene und der Drohne (Apis mellifica L). Z Vergl Physiol 48: 587623.

Lefebvre L, Sol D. 2008. Brains, lifestyles and cognition: are there general trends? Brain Behav Evol 72:135 144.

Michener CD. 2007. The bees of the world, 2nd ed. Balti more: Johns Hopkins University Press. 992 p.

Molina Y, O'Donnell S. 2007. Mushroom body volume is related to social aggression and ovary development in the paperwasp Polistes instabilis. Brain Behav Evo 170: 137144.

Mysore K, Subramanian KA, Sarasij RC, Suresh A, Shyamala BV, VijayRaghavan K, Rodrigues V. 2009. Caste and sex specific olfactory glomerular organization and brain archi tecture in two sympatric ant species Camponotus sericeus and Camponotus compressus (Fabricius, 1798). Arthropod Struct Dev 38:485 497.

Mysore K, Shyamala BV, Rodrigues V. 2010. Morphological and developmental analysis of peripheral antennal chemo sensory sensilla and central olfactory glomeruli in worker castes of Camponotus compressus (Fabricius, 1787). Ar thropod Struct Dev 39:310 321 .

Nakanishi A, Nishino H, Watanabe H, Yokohari F, Nishikawa M. 2009. Sex specific antennal sensory system in the ant Camponotus japonicus: structure and distribution of sen silla on the flagellum. Cell Tissue Res 338:79 97.

Nakanishi A, Nishino H, Watanabe H, Yokohari F, Nishikawa M. 2010. Sex specific antennal sensory system in the ant Camponotus japonicus: glomerular organizations of anten nal lobes. J Comp Neurol 518:2186 2201.

Nishikawa M, Nishino H, Misaka Y, Kubota M, Tsuji E, Satoji Y, Ozaki M, Yokohari F. 2008. Sexual dimorphism in the antennal lobe of the ant Camponotus japonicus. Zool Sci 25:195 204.

Nishino H, Nishikawa M, Mizunami M, Yokohari F. 2009. Func tional and topographic segregation of glomeruli revealed by local staining of antennal sensory neurons in the honey bee Apis mellifera. J Comp Neurol 515:161 180.

Ohtani T. 1974. Behavior repertoire of adult drone honeybee within observation hives. J Fac Sci Hokkaido Univ 19: 706721.

Ott SR, Rogers SM. 2010. Gregarious desert locusts have substantially larger brains with altered proportions com pared with the solitarious phase. Proc Biol Sci 277: 30873096.

Ozaki M, Wada Katsumata A, Fujikawa K, Iwasaki M, Yokohari F, Satoji Y, Nisimura T, Yamaoka R. 2005. Ant nestmate and non nestmate discrimination by a chemosensory sen sillum. Science 309:311 314.

Paxton RJ. 2005. Male mating behaviour and mating systems of bees: an overview. Apidologie 36:145 156.

Priesner E. 1973. Reaktionen von Riechrezeptoren männlicher Solitärbienen (Hymenoptera, Apoidea) auf Inhaltsstoffe von Ophrys Blüten. Zoon Suppl 1:43 54.
Renner M, Vierling G. 1977. Die Rolle des Taschendrüsenpher omons beim Hochzeitsflug der Bienenkönigin. Behav Ecol Sociobiol 2:329 338.

Riveros AJ, Gronenberg W. 2010. Sensory allometry, foraging task specialization and resource exploitation in honeybees. Behav Ecol Sociobiol 64:955 966.

Ruchty M, Romani R, Kuebler LS, Ruschioni S, Roces F, Isi doro N, Kleineidam CJ. 2009. The thermo sensitive sensilla coeloconica of leaf cutting ants (Atta vollenweideri). Arthro pod Struct Dev 38:195 205.

Sandoz JC. 2006. Odour evoked responses to queen phero mone components and to plant odours using optical imag ing in the antennal lobe of the honey bee drone Apis mellifera L. J Exp Biol 209:3587 3598.

Schachtner J, Schmidt M, Homberg U. 2005. Organization and evolutionary trends of primary olfactory brain centers in Tetraconata (Crustacea + Hexapoda). Arthropod Struct Dev 34:257 299

Shimron O, Hefetz A. 1985. Mating behavior and sex attrac tion of Eucera palestinae Friese (Hymenoptera, Anthophori dae). J Kansas Entomol Soc 58:526 531.

Smith AR, Seid MA, Jimenez LC, Wcislo WT. 2010. Socially induced brain development in a facultatively eusocial sweat bee Megalopta genalis (Halictidae). Proc R Soc Lond B Biol Sci 277:2157 2163.

Stieb SM, Kelber C, Wehner R, Rössler W. 2011. Antennal lobe organization in desert ants of the genus Cataglyphis. Brain Behav Evolut 77:136 146.

Strausfeld N, Reisenman CE. 2009. Dimorphic olfactory lobes in the Arthropoda. Ann N Y Acad Sci 1170:487 496.

Strausfeld NJ, Hansen L, Li Y, Gomez RS, Ito K. 1998. Evolu tion, discovery, and interpretations of arthropod mushroom bodies. Learn Mem 5:11 37.

Streinzer M, Paulus HF, Spaethe J. 2009. Floral colour signal increases short range detectability of a sexually deceptive orchid to its bee pollinator. J Exp Biol 212:1365 1370.

Stubblefield JW, Seger J. 1994. Sexual dimorphism in the Hy menoptera. In: Short RV, Balaban E, editors. The differen ces between the sexes. New York: Cambridge University Press. p 71103.

Swallow JG, Wilkinson GS, Marden JH. 2000. Aerial perform ance of stalk eyed flies that differ in eye span. J Comp Physiol B 170:481 487.

Symonds MR, Johnson TL, Elgar MA. 2012. Pheromone pro duction, male abundance, body size, and the evolution of elaborate antennae in moths. Ecol Evol 2:227 246.

Vareschi E. 1971. Duftunterscheidung bei der Honigbiene Ein zelzell Ableitungen und Verhaltensreaktionen. Z Vergl Phys iol 75:143 173.

Vosshall LB, Hansson BS. 2011. A unified nomenclature sys tem for the insect olfactory coreceptor. Chem Senses 36: 497498.

Wanner KW, Nichols AS, Walden KKO, Brockmann A, Luetje CW, Robertson HM. 2007. A honey bee odorant receptor for the queen substance 9 oxo 2 decenoic acid. Proc Natl Acad Sci U S A 104:14383 14388.

Winston ML. 1991. The biology of the honey bee. Cambridge, MA: Harvard University Press. $281 \mathrm{p}$.

Withers GS, Fahrbach SE, Robinson GE. 1993. Selective neu roanatomical plasticity and division of labour in the honey bee. Nature 364:238 240.

Withers GS, Day NF, Talbot EF, Dobson HEM, Wallace CS. 2008. Experience dependent plasticity in the mushroom bodies of the solitary bee Osmia lignaria (Megachilidae). Dev Neurobiol 68:73 82.

Zube C, Rössler W. 2008. Caste and sex specific adaptations within the olfactory pathway in the brain of the ant Campo notus floridanus. Arthropod Struct Dev 37:469 479. 